\title{
Psoriasis assessment tools in clinical trials
}

\author{
S R Feldman, G G Krueger
}

Ann Rheum Dis 2005;64(Suppl II):ii65-ii68. doi: 10.1136/ard.2004.031237

In clinical practice, broad global assessments of psoriasis disease activity and its effect on patients' quality of life are used to assess the severity of patients' disease and their response to treatment. In clinical trials, more objective, validated instruments are required. Several such instruments have been developed and continue to be developed to provide an assessment of the severity of the skin lesions. Because a lesion's impact on patients' lives varies widely among patients, there has been growing recognition of the need to measure the quality of life impact of the disease along with the severity of the lesions.

$\mathrm{T}$ he measurement of psoriasis disease activity in clinical practice is very straightforward. Physicians ask their patients how they are doing, and patients report their perceptions of the severity of their disease. By combining this subjective report with the physician's global assessment of the severity of the lesions, the physician makes a determination of how severe the disease is and how well the patient is progressing with therapy.

Clinical trials of psoriasis present a greater challenge for measurement of psoriasis disease activity/severity. Objective measures are needed that are reliable, valid, and consistent from investigator to investigator. Fortunately, psoriasis lesions are quite visible and therefore relatively easy to quantify; unfortunately, simple quantitation of the lesions is not a complete assessment of severity, as the impact of the lesions is experienced differently by different patients. As discussed below, tools now exist to measure the character and extent of psoriasis lesions and there are other measures used to assess the effect of psoriasis on patients' quality of life.

\section{TRADITIONAL ASSESSMENT TOOLS}

The basic characteristics of psoriasis lesions-redness, thickness, and scaliness-provide a means of assessing the severity of psoriasis. The current gold standard for assessment of extensive psoriasis has been the Psoriasis Area and Severity Index (PASI). ${ }^{1}$ The PASI is a measure of the average redness, thickness, and scaliness of the lesions (each graded on a $0-4$ scale), weighted by the area of involvement (table 1). While the PASI has been the most widely used measure, it does have a number of limitations, one of which is its poor sensitivity to change for relatively small areas of involvement (table 2). In studies involving treatment for localised plaques of psoriasis, target lesion assessments are generally performed that also measure the redness, thickness, and scaliness of target plaques.

Another key measure used in clinical trials of psoriasis is the physician global assessment (PGA; table 3). Global assessments can be done for extensive disease as well as localised plaques. There are two primary forms: a static form, which measures the physician's impression of the disease at a single point, and a dynamic form in which the physician assesses the global improvement from baseline. Because the latter requires the dubious assumption that physicians can remember the severity of psoriasis at baseline over the course of the trial, the static PGA has become the standard. Although the PASI is probably the gold standard for assessment of severe psoriasis (and PGA is also widely used), there have been few validation studies, and the construct validity, face validity, and sensitivity to change are not well characterised. $^{2}$

When conducting a clinical trial for treatment for psoriasis, a predetermined primary endpoint is required on which the efficacy of the drug will be assessed. ${ }^{3}$ This endpoint must demonstrate that more patients achieve clinically meaningful success with the drug treatment than with placebo. Determining a definition for "clinically meaningful success" is somewhat problematic in psoriasis. For patients with severe psoriasis, clinicians typically consider at least $75 \%$ improvement in disease to be a clinically meaningful improvement indicative of success. This has been translated into $75 \%$ improvement in the PASI score; however, it is clear that patients with far lower improvements in the PASI score also can have clinically meaningful improvement in their disease. Quality of life measures are helpful for demonstrating that changes in the severity of the skin lesions correspond to improvement in patients' lives. One advantage of the PASI score is that it is now well established that $75 \%$ improvement in PASI (PASI 75) is a clinically meaningful endpoint for clinical trials, and there is strong evidence demonstrating that $50 \%$ improvement in PASI (PASI 50) is also a clinically meaningful endpoint. ${ }^{4}$ A major limitation of the PASI is that it is not routinely used by clinicians and therefore is poorly understood by both clinicians and patients (see table 2). Physician global assessments that are used in trials are far easier to understand and are more similar to the assessments physicians actually perform in clinical practice.

\section{MORE RECENT ASSESSMENT TOOLS}

Other important psoriasis measurement tools are being developed. The lattice system provides a global psoriasis score that ranges over eight steps from clear to very severe. ${ }^{5}$ The investigator rates the elevation (also termed induration or thickness in other measures), erythema, and scaliness of the lesion, each on a none to mild, moderate, marked scale. The percentage of body surface area involved is also measured in categories of $0 \%, 1-3 \%, 4-9 \%, 10-20 \%, 21-$ $29 \%, 30-50 \%$, and $51-100 \%$. By combining these areas of involvement with the character of the plaques, the psoriasis can be categorised into one of eight categories on the clear to very severe scale. This system shows a good correlation with both physician global assessment and PASI scores and provides better intrarater and interrater reliability than PASI. ${ }^{5}$ Although it first appears difficult to use, with experience the lattice system actually becomes quite easy to

Abbreviations: DLQI, Dermatology Life Quality Index; NPF-PS, National Psoriasis Foundation Psoriasis Score; PASI, Psoriasis Area and Severity Index; PGA, physician global assessment 
Table 1 Elements of the Psoriasis Area and Severity Index (PASI)*

\begin{tabular}{lllll}
\hline & Head & Upper extremities & Trunk & \\
\hline 1 & Redness & & & \\
2 & Thickness & & & \\
3 & Scale $†$ & & & \\
4 & Sum of rows 1,2 , and 3 & row $4 \times$ row $5 \times 0.3$ \\
5 & Area score $\neq$ & row $4 \times$ row $5 \times 0.1$ & row $4 \times$ row $5 \times 0.2$ & \\
6 & Score of row $4 \times$ row $5 \times$ the area multiplier & & & \\
7 & Sum row 6 for each column for PASI score & & & \\
\hline
\end{tabular}

*Steps in generating PASI score

(a) Divide body into four areas: head, arms, trunk to groin, and legs to top of buttocks.

(b) Generate an average score for the erythema, thickness, and scale for each of the 4 areas $(0=$ clear; $1-4=$ increasing severity $)$ t.

(c) Sum scores of erythema, thickness, and scale for each area.

(d) Generate a percentage for skin covered with psoriasis for each area and convert that to a $0-6$ scale $(0=0 \% ; 1=<10 \% ; 2=10-<30 \% ; 3=30-<50 \% ; 4=50-$

$<70 \% ; 5=70-<90 \% ; 6=90-100 \%$ ).

(e) Multiply score of item (c) above times item (d) above for each area and multiply that by $0.1,0.2,0.3$, and 0.4 for head, arms, trunk, and legs, respectively.

(A) Add these scores to get the PASI score.

†Erythema, induration and scale are measured on a 0-4 scale (none, slight, mild, moderate, severe)

$\ddagger$ Area scoring criteria (score: \% involvement)

$0: 0$ (clear)

$1:<10 \%$

2: $10-<30 \%$

3: $30-<50 \%$

4: $50-<70 \%$

5: $70-<90 \%$

6: $90-<100 \%$

use and provides a static step score that has meaning for both doctors and patients. Still, determining what endpoint is clinically significant will need to be addressed. Is a one step change meaningful (for example, going from very severe to severe), or should a change of two or more steps be required? It is to be appreciated that the Food and Drug Administration (FDA), at this time, prefers a step score endpoint as it is believed to be more reflective of a physician's assessment in non-study settings.

The National Psoriasis Foundation (NPF) has developed the NPF Psoriasis Score (NPF-PS), a responder index, that include six subdomains: induration at two target sites, current and baseline body surface area, physician global assessment, patient global assessment, and patient assessment of itch (table 4). ${ }^{67}$ To help improve intrarater and interrater reliability of the induration score, the NPF-PS utilises a reference card embossed with elevations that increase at $0.25 \mathrm{~mm}$ intervals.

Two other quantitative ways of measuring psoriasis are biopsies and photographs. Biopsies are attractive because they are objective-however, their major limitation is that psoriasis does not resolve in a uniform fashion, and therefore biopsies may not provide a representative sampling of lesions. Nevertheless, histological changes, decrease in epidermal thickness, and loss of K16 in biopsies taken after 30 days of therapy will predict outcome weeks to months later. ${ }^{8}$ Histological evaluations can be objective and are useful for assessing biomarkers of improvement as well as following pharmacodynamic endpoints. In theory, photography could be used to confirm real time assessments of disease severity. It is not clear, however, if thickness/induration or even scaliness of lesions can be accurately assessed using the photographs. Nevertheless, photographs do make a strong impact in educating physicians and are therefore commonly incorporated into clinical trials.

A major component of the assessment of psoriasis now is the measurement of quality of life. Measures of quality of life do not directly measure the impact of a drug on disease, however, they do measure the impact of the disease and the ability of treatment to improve patients' lives. Because improving patients' lives is the primary goal of therapy, quality of life measures are very important. ${ }^{9}{ }^{10}$ Nevertheless, the primary outcome in clinical trials almost certainly will remain the relatively more objective measures of disease severity. The tools listed in tables 2 and 3, with the exception of the NPF-PS, do not assess this impact. Some patients have lots of lesions but are not bothered by them, and some patients have very few lesions and are greatly bothered by them. Treatments that improve lesions but do not improve quality of life are not providing a clinically meaningful

Table 2 Pros and cons for selected tools to assess response to treatment

\begin{tabular}{|c|c|c|c|c|}
\hline & $\begin{array}{l}\text { Psoriasis Area and Severity Index } \\
\text { (PASI) }\end{array}$ & $\begin{array}{l}\text { National Psoriasis Foundation Psoriasis } \\
\text { Score } \\
\text { (NPF-PS) }\end{array}$ & $\begin{array}{l}\text { Physician static global assessment } \\
\text { (PSGA) }\end{array}$ & $\begin{array}{l}\text { Overall lesion assessment } \\
\text { (OLA) }\end{array}$ \\
\hline Pros & $\begin{array}{l}\text { Widely used } \\
\text { Correlates to QoL, albeit poorly } \\
\text { Accepted by approving agencies }\end{array}$ & $\begin{array}{l}\text { Correlates with QoL } \\
\text { Discriminates when BSA is low } \\
\text { Has patient input } \\
\text { Thickness is predominate component } \\
\text { All elements are defined }\end{array}$ & $\begin{array}{l}\text { Simple } \\
\text { Forces evaluator to step increments } \\
\text { (not a continuous scale) }\end{array}$ & $\begin{array}{l}\text { Simple } \\
\text { Forces step increments } \\
\text { (not a continuous scale) } \\
\text { Uses thickness of lesions }\end{array}$ \\
\hline Cons & $\begin{array}{l}\text { Not used by clinicians } \\
\text { FDA wants tool that reflects } \\
\text { clinical use } \\
\text { Does not discriminate when BSA } \\
\text { is low } \\
\text { Upper end of scale not used }\end{array}$ & $\begin{array}{l}\text { Is not linear } \\
\text { Has not been widely tested } \\
\text { Not yet accepted by approving agencies } \\
\text { nor clinicians }\end{array}$ & $\begin{array}{l}\text { Does not discriminate small changes } \\
\text { Range not robust }\end{array}$ & $\begin{array}{l}\text { Does not discriminate small changes } \\
\text { Range not robust, correlation to PASI } \\
\text { unknown }\end{array}$ \\
\hline
\end{tabular}


Table 3 Elements of four global assessment scores in rating psoriasis

\begin{tabular}{|c|c|c|c|}
\hline $\begin{array}{l}\text { Lattice System Global Psoriasis Score } \\
\text { (LS- GPS) }\end{array}$ & $\begin{array}{l}\text { Physician static global } \\
\text { assessment (PSGA) score }\end{array}$ & $\begin{array}{l}\text { Physician dynamic global } \\
\text { assessment (PDGA) score }\end{array}$ & $\begin{array}{l}\text { Overall lesion assessment } \\
\text { (OLA) }\end{array}$ \\
\hline Global score & Usually used as a 7 point score & Usually used as a 7 point score & 5 point scale \\
\hline $\begin{array}{l}\text { Range: } 8 \text { steps (clear to very severe) } \\
\text { step scores }\end{array}$ & $\begin{array}{l}0=\text { clear; scores } 1-6=\text { increasing } \\
\text { severity }\end{array}$ & $\begin{array}{l}0=\text { clear; scores of } 1-5=\text { increasing } \\
\text { severity; } 6=\text { worsened }\end{array}$ & $0=$ none $; 4=$ very severe \\
\hline Plaque qualities defined & Requires definition of each score & $\begin{array}{l}\text { Requires recall memory or } \\
\text { assisted with baseline } \\
\text { photograph }\end{array}$ & $\begin{array}{l}\text { Photo guideline provided to assist } \\
\text { scoring the two components }\end{array}$ \\
\hline \multirow[t]{2}{*}{$\begin{array}{l}\text { Weights elevation (induration) } \\
\text { preferentially }\end{array}$} & & & $\begin{array}{l}\text { Component } 1 \text { = thickness score, composite } \\
\text { of all lesions }\end{array}$ \\
\hline & & & $\begin{array}{l}\text { Component } 2=\text { erythema and scaling score, } \\
\text { composite of all lesions }\end{array}$ \\
\hline
\end{tabular}

benefit. In general, there is correlation between quality of life measures and changes in the more objective measures such as PASI and PGA; however, the correlation is far less than 1:1 (see table 2 ).

Quality of life can be measured at different levels. Nonspecific measures such as the Medical Outcome Survey Short Form 36 (SF-36), the Euro QoL, and utility measures assess patients' overall quality of life. ${ }^{11}{ }^{12}$ There are more specific instruments that focus on aspects of quality of life that are affected by skin disease. These include the Dermatology Life Quality Index (DLQI) and the Skindex.. ${ }^{13}{ }^{14}$ There are even psoriasis specific measures. The generic measures, such as the SF-36, are useful for showing the impact of psoriasis relative to other medical diseases. The SF-36 was used to show that the impact of psoriasis was as great or greater than many other serious medical conditions. ${ }^{15}$ The DLQI has been most widely used measure for assessing quality of life related to skin disease in psoriasis trials. ${ }^{13}$ This instrument consists of 10 questions covering six domains (symptoms and feelings, daily activities, leisure, work and school, personal relationships, and bother with psoriasis treatment). The response options range from 0 , not affected at all, to 3 , very much affected. This gives an overall range of 0-30 where lower scores mean better quality of life. The reliability, construct validity, and sensitivity to change of the DLQI have all been demonstrated in psoriasis patients. ${ }^{16}$ Another score that includes psychological impact along with the severity of the skin lesions is the Salford Psoriasis Index (SPI). ${ }^{17}$ This measure includes the extent of psoriasis, the psychosocial impact of the disease, and the intensity of previous psoriasis treatments. The psychosocial impact component showed good correlation $(r=0.59)$ with the Psoriasis Disability Index, and the extent of psoriasis component showed good interrater reliability $(r=0.70){ }^{17}$

Trials of new agents-such as alefacept, efalizumab, and tumour necrosis factor $\alpha(\mathrm{TNF} \alpha)$ inhibitors such as etanercept and infliximab-have demonstrated that patients'

Table 4 Elements of National Psoriasis Foundation Psoriasis Score (NPF-PS)

\begin{tabular}{|c|c|}
\hline & Score \\
\hline Induration of representative target lesion A (0-1.25 mm) & $0-5$ \\
\hline Induration of representative target lesion $B(0-1.25 \mathrm{~mm})$ & $0-5$ \\
\hline $\begin{array}{l}\text { Body surface area relative to baseline as \% (score is } 20 \% \\
\text { intervals) }\end{array}$ & $0-5$ \\
\hline Physician global assessment (static and defined) & $0-5$ \\
\hline $\begin{array}{l}\text { Patient global assessment (relative to worst disease has ever } \\
\text { been) }\end{array}$ & $0-5$ \\
\hline $\begin{array}{l}\text { Patient assessment of itch (defined score = average over } \\
24 \text { hours) }\end{array}$ & $0-5$ \\
\hline
\end{tabular}

quality of life clearly improves with treatment. ${ }^{18-23}$ Detailed examination of some of these trials has shown that even in those patients who achieve only $50 \%$ improvement in the PASI, but not $75 \%$ improvement in the PASI, have significant improvement in their DLQI scores, meaning that patients with this level of improvement in the skin lesions are achieving clinical significant improvement in their quality of life. $^{4}$

An important feature of the quality of life score is that it is complementary to the lesion severity scores. For example, mean PASI scores may show statistically significant improvement early in clinical trials, and quality of life measures can be used to confirm that these changes are clinically meaningful. For example, in etanercept trials, quality of life measured by DLQI was improved four weeks into the course of treatment, confirming the clinical significance of early PASI changes. ${ }^{21}$

A final assessment that may be of value in the future is genomics. These studies may lead to better mechanistic understanding of psoriasis. For treatment purposes, genomics may also be particularly helpful for providing prognostic information and for guiding treatment recommendations that may provide patients the maximum benefit with the fewest side effects. ${ }^{24}$

\section{SUMMARY}

In conclusion, there is no one "best" measure for use in clinical trials. The PASI, along with physician global assessment and quality of life measures, provide a complement of measures for studies of moderate to severe psoriasis that offer objectivity, are understandable to clinicians, and yield a comprehensive view of the impact of disease. Radically changing psoriasis measurement in future trials would have the further disadvantage of making it difficult to compare the efficacy of new agents to established agents that had been tested under the previous measurement paradigm. However, recent clinical trials in psoriasis have clearly shown that the PASI was not a way to measure therapeutic response in those patients who had a PASI $<3$; a standardised assessment tool that effectively measures small amounts of psoriasis is needed. Target lesion severity score, supplemented by physician global assessment and quality of life measures, is the current standard, but the NPF-PS may prove to be an effective approach. If it works well in clinical trials, the NPF-PS would have the advantage of assessing response or natural history of all forms of plaque psoriasis.

\section{Authors' affiliations}

S R Feldman, Department of Dermatology, Wake Forest University School of Medicine, Winston-Salem, NC, USA

G G Krueger, Department of Dermatology, University of Utah Health Sciences Center, Salt Lake City, UT, USA 
Correspondence to: Dr S R Feldman, Wake Forest University School of Medicine, Department of Dermatology, Medical Center Boulevard, Winston-Salem, NC 27157-1071, USA; sfeldman@wfubmc.edu

\section{REFERENCES}

1 Fredriksson T, Pettersson U. Severe psoriasis-oral therapy with a new retinoid. Dermatologica 1978;157:238-44.

2 Ashcroft DM, Wan Po AL, Williams HC, Griffiths CE. Clinical measures of disease severity and outcome in psoriasis: a critical appraisal of their quality. Br J Dermatol 1999; 141:185-91.

3 Feldman SR. The design of clinical trials in psoriasis: lessons for clinical practice. J Am Acad Dermatol 2003;49:S62-S65.

4 Carlin CS, Feldman SR, Krueger JG, Menter A, Krueger GG. A 50\% reduction in the Psoriasis Area and Severity Score (PASI 50) is a clinically significant endpoint in the assessment of psoriasis. J Am Acad Dermatol 2004;50:859-66

5 Langley RG, Ellis CN. Evaluating psoriasis with Psoriasis Area and Severity Index, Psoriasis Global Assessment, and Lattice System Physician's Global Assessment. J Am Acad Dermatol 2004:51:563-9.

6 Carlin CS, Callis KP, Krueger GG. Efficacy of acitretin and commercial tanning bed therapy for psoriasis. Arch Dermatol 2003;139:436-42

7 Gottlieb AB, Chaudhari U, Baker DG, Perate M, Dooley LT. The National Psoriasis Foundation Psoriasis Score (NPF-PS) system versus the Psoriasis Area Severity Index (PASI) and Physician's Global Assessment (PGA): a comparison. J Drugs Dermatol 2003;2:260-6.

8 Krueger JG, Wolfe JT, Nabeya RT, Vallat VP, Gilleaudeau P, Heftler NS, et al. Successful ultraviolet $B$ treatment of psoriasis is accompanied by a reversal of keratinocyte pathology and by selective depletion of intraepidermal T cells. J Exp Med 1995; 182:2057-68.

9 Krueger GG, Feldman SR, Camisa C, Duvic M, Elder JT, Gottlieb AB, et al. Two considerations for patients with psoriasis and their clinicians: What defines mild, moderate, and severe psoriasis? What constitutes a clinically significant improvement when treating psoriasis? J Am Acad Dermatol 2000;43:280-5

10 Kirby B, Richards HL, Woo P, Hindle E, Main CJ, Griffiths CE. Physical and psychologic measures are necessary to assess overall psoriasis severity. J Am Acad Dermatol 2001;45:72-6.
11 Anderson RT, Aaronson NK, Wilkin D. Critical review of the international assessments of health-related quality of life. Qual Life Res 1993;2:369-95. 12 Brazier J, Jones N, Kind P. Testing the validity of the Euroqol and comparing it with the SF-36 health survey questionnaire. Qual Life Res 1993;2:169-80.

13 Finlay AY, Khan GK. Dermatology Life Quality Index (DLQI)-a simple practical measure for routine clinical use. Clin Exp Dermato 1994;19:210-16.

14 Chren MM, Lasek RJ, Flocke SA, Zyzanski SJ. Improved discriminative and evaluative capability of a refined version of Skindex, a quality-of-life instrument for patients with skin diseases. Arch Dermatol 1997; 133:1433-40.

15 Rapp SR, Feldman SR, Exum ML, Fleischer AB Jr, Reboussin DM. Psoriasis causes as much disability as other major medical diseases. J Am Acad Dermatol 1999:41:401-7.

16 Ashcroft DM, Li Wan Po A, Williams HC, Griffiths CE. Quality of life measures in psoriasis: a critical appraisal of their quality. J Clin Pharm Ther 1998;23:391-8.

17 Kirby B, Fortune DG, Bhushan M, Chalmers RJ, Griffiths CE. The Salford Psoriasis Index: an holistic measure of psoriasis severity. Br J Dermatol 2000; 142:728-32

18 Ellis CN, Mordin MM, Adler EY. Effects of alefacept on health-related quality of life in patients with psoriasis: results from a randomized, placebo-controlled phase II trial. Am J Clin Dermatol 2003:4:131-9.

19 Gordon KB, Papp KA, Hamilton TK, Walicke PA, Dummer W, Li N, et al. Efalizumab Study Group. Efalizumab for patients with moderate to severe plaque psoriasis: a randomized controlled trial, JAMA 2003;290:3073-80. Erratum in: JAMA 2004;291:1070.

20 Leonardi CL, Powers JL, Matheson RT, Goffe BS, Zitnik R, Wang A, et al. Etanercept Psoriasis Study Group. Etanercept as monotherapy in patients with psoriasis. N Engl J Med 2003;349:2014-22.

21 Gottlieb AB, Matheson RT, Lowe N, Krueger GG, Kang S, Goffe BS, et al. A randomized trial of etanercept as monotherapy for psoriasis. Arch Dermatol 2003;139:1627-32.

22 Gottlieb AB. Infliximab for psoriasis. J Am Acad Dermatol 2003;49:S112-S117.

23 Gottlieb AB, Chaudhari U, Mulcahy LD, Li S, Dooley LT, Baker DG. Infliximab monotherapy provides rapid and sustained benefit for plaque-type psoriasis. J Am Acad Dermatol 2003;48:829-35.

24 Elder JT. Psoriasis clinical registries, genetics, and genomics. Ann Rheum Dis 2005;64(suppl II):ii106-7. 